\title{
Studies of the Cyclopolymerization in the Presence of Alkylalminum Chlorides. IV. Polymerization of $o$-Vinylphenyl Acrylate
}

\author{
Toyoji KakuchI, Kazuaki Yokota, and Yoshiyuki Takada \\ Department of Chemical Process Engineering, Faculty of Engineering, \\ Hokkaido University, Sapporo 060, Japan.
}

(Received December 26, 1977)

\begin{abstract}
In the cyclopolymerization of $o$-vinylphenyl acrylate (VPA) with a conventional radical initiator and with alkylaluminum chlorides, polymers containing residual acrylic and vinylic double bonds were obtained. The cyclic structure and the sequence in the polymers were investigated by IR and NMR spectra of methylated polymers, in comparison with those of random and alternating copolymers of $o$-methoxystyrene-methyl acrylate; the methylated polymers were derived from the diazomethane treatment after the hydrolysis of the original cyclized polymers. The IR spectra indicated that the polymerization of VPA proceeded through head-to-tail additions with the cyclic structure of a seven-membered ring. There was a distinct difference of methoxy proton resonance in the NMR spectra of the methylated polymers derived from cyclized polymers prepared with a conventional radical initiator and in the presence of alkylaluminum chlorides. The spectrum of the former corresponded with that of the random copolymer and the spectra of the latter with that of the alternating copolymers. On the basis of the NMR measurement, the sequence of addition of the acrylic and the vinylic double bonds was random for the radical cyclopolymerization, and alternating for the cyclopolymerization in the presence of alkylaluminum chlorides. The cyclopolymerization in the presence of alkylaluminum chlorides was explained by the molecular complex mechanism.
\end{abstract}

KEY WORDS $o$-Vinylphenyl Acrylate / Cyclopolymerization / Radical Polymerization / Alkylaluminum Chlorides / Methyl Acrylate / oMethoxystyrene / Alternating Copolymer / Head-to-Tail Addition / Seven-membered Ring / Molecular Complex /

It has been well known that the cyclopolymerization tendency generally depends on the ring size and falls sharply for rings of more than six atoms in the cyclopolymerizations of nonconjugated diolefins. $^{1} \quad$ As one of the driving forces for cyclization, an intramolecular interaction between two double bonds in the polymerization process is important. $^{2-4}$ Thus, if it is possible to find the reaction conditions causing such an interaction for diolefins, an increase in cyclopolymerization tendency can be expected.

The authors have reported that the addition of alkylaluminum chlorides to $o$-allylphenyl acrylate (APA) $)^{5}$ 2-(o-allylphenoxy)ethyl acrylate (2AOEA), ${ }^{6}$ and 4-(o-allylphenoxy)butyl acrylate (4AOBA) ${ }^{6}$ caused an increase in their cyclopolymerization tendency and gave highly cyclized poly- mers containing eight-, eleven-, and thirteen-membered rings, respectively. The cyclopolymerization tendency slightly decreased upon increasing the number of atoms between the acrylic and the allylic double bond, in the order of APA $>2$ AOEA $>4$-AOBA. Even for 2-AOEA and 4AOBA, however, the values of $k_{\mathrm{p}} / k_{\mathrm{c}}$, the ratio of rate constants for the linear propagation and cyclization, were comparable to the value for acrylic anhydride, ${ }^{7}$ a symmetrical 1, 6-diene, in the radical polymerization. These results suggest that the addition of alkylaluminum chlorides caused the formation of an intramolecular interaction between the two double bonds in the polymerization process.

Therefore, it is interesting to see how alkylaluminum chlorides affect the cyclopolymerization 
of the analogous monomer forming a smaller ring than APA, since such a monomer should generally possess a greater cyclization tendency. The present paper reports the cyclopolymerization of $o$ vinylphenyl acrylate, which gives polymers containing seven-membered rings.

\section{EXPERIMENTAL}

\section{Reagents}

Monomers. $o$-Vinylphenyl acrylate was prepared by the reaction of $o$-vinylphenol ${ }^{8}$ and acryloyl chloride. The fraction boilling at 97$99^{\circ} \mathrm{C}(4 \mathrm{~mm})$ was collected: $n_{\mathrm{D}}^{20} 1.5485 ; d_{4}^{15} 1.0734$ Anal. Calcd for $\mathrm{C}_{11} \mathrm{H}_{10} \mathrm{O}_{2}:$ C, 75.84; $\mathrm{H}, 5.79$. Found: C, 75.89; H, 5.90.

$o$-Methoxystyrene was obtained from $O$-methylation of $o$-vinylphenol by dimethyl sulfate. $o$ Vinylphenyl acetate was prepared from $o$-vinylphenol and acetyl chloride, and $o$-cresyl acrylate from $o$-cresol and acryloyl chloride. Methyl acrylte was commercially obtained.

Alkylaluminum Chlorides. Diethylaluminum chloride, ethylaluminum sesquichloride, and ethylaluminum dichloride were kindly supplied by Mitsui Petrochemical Industries, Ltd.

\section{Polymerization}

The polymerizations were carried out as described in a previous paper. ${ }^{5}$ For the polymerization of VPA in the presence of $\mathrm{AlEt}_{2} \mathrm{Cl}$ the reaction system was homogeneous. In the presence of $\mathrm{AlEt}_{1.5} \mathrm{Cl}_{1.5}$ and $\mathrm{AlEtCl}_{2}$, a slurry precipitate formed as the reaction proceeded. All the polymers obtained, even in homogeneous polymerization system, were insoluble in benzene, chloroform, and other organic solvents.

The methylated polymers were derived from treatment with diazomethane after the hydrolysis of the polymers obtained, as described in a previous paper. ${ }^{5}$

The random copolymer of $o$-methoxystyrene and methyl acrylate was prepared with AIBN at $60^{\circ} \mathrm{C}$. The alternating copolymer was obtained in the presence of $\mathrm{AlEt}_{1.5} \mathrm{Cl}_{1.5}$ according to the described method. ${ }^{9}$

The copolymerization of $o$-vinylphenyl acetate and $o$-cresyl acrylate was carried out in the presence of alkylaluminum chlorides in the described manner. ${ }^{9}$

\section{Analysis}

Determination of the Mole Fraction of Residual Double Bonds in Polymers. The mole fraction of acrylic and vinylic double bonds $\left(f_{\mathrm{a}}\right.$ and $\left.f_{\mathrm{v}}\right)$ was determined by measuring the ratio of the optical densities at 1410 and $1490 \mathrm{~cm}^{-1}\left(D_{1410} / D_{1490}\right)$, and 920 and $1490 \mathrm{~cm}^{-1}\left(D_{920} / D_{1490}\right)$. The calibration curves were made using the following specimens as the standard for $f_{\mathrm{a}}$ and $f_{\mathrm{v}}$ : the polymer obtained from the anionic polymerization of VPA $\left(f_{\mathrm{a}}=0\right.$, $f_{\mathrm{v}}=1.0$ ); the polymer obtained from the radical polymerization of VPA at low monomer concentration $\left(f_{\mathrm{v}}=0\right)$; the VPA monomer $\left(f_{\mathrm{a}}=1.0\right)$.

Determination of the Copolymer Composition. The composition in the copolymers of $o$-vinylphenyl acetate- $o$-cresyl acrylate was determined according to gas chromatographic technique for $o$-cresol which formed when the copolymers were hydrolyzed with $10-\%$ methanolic potassium hydroxide.

Measurements. Infrared measurements were carried out with a Shimadzu IR-430 infrared spectrophotometer. The NMR spectra of the methylated polymers and the copolymers were obtained at $35^{\circ} \mathrm{C}$ in deuterated chloroform as about $10-\%$ solution, using a Hitachi R-22 high resolution NMR spectrometer.

\section{RESULTS AND DISCUSSION}

\section{Polymerization of o-Vinylphenyl Acrylate (VPA)}

The results of the radical polymerization in benzene solutions are given in Table I. The polymers obtained were soluble in chloroform. The IR spectra of monomer and its polymer are shown in Figures 1 and 2, respectively. The IR spectrum of the polymer indicates the presence of an acrylic and a vinylic double bond which are observed by the absorption bands at 1410 and $920 \mathrm{~cm}^{-1}$, respectively. The mole fraction of the residual acrylic double bonds $\left(f_{\mathrm{a}}\right)$ was larger than that of the residual vinylic double bonds $\left(f_{\nabla}\right)$. All the vinylic double bonds and the majority of the acrylic double bonds were consumed at the monomer concentration of $2.01 \mathrm{~mol} l^{-1}$ or below. The mole fraction of cyclic structural units $\left(f_{\mathrm{c}}\right)$, calculated from the equation of $f_{\mathrm{c}}=1-\left(f_{\mathrm{a}}+f_{\mathrm{v}}\right)$, increased with a decrease in the monomer concentration, as is generally found in cyclopolymerization, and was 0.71 at the monomer concentration 
Table I. Radical polymerization of $o$-vinylphenyl acrylate $^{\mathrm{a}}$

\begin{tabular}{crrrrl}
\hline $\begin{array}{c}\text { [M] } \\
\text { mol } l^{-1}\end{array}$ & $\begin{array}{r}\text { Time, Conversion, } \\
\text { min }\end{array}$ & $\begin{array}{c}f_{\mathrm{a}}{ }^{\mathrm{b}} \\
{ }^{2}\end{array}$ & $f_{\mathrm{v}}{ }^{\mathrm{c}}$ & \multicolumn{1}{c}{$f_{\mathrm{c}} \mathrm{d}$} \\
\hline 6.16 & 20 & 2.5 & 0.645 & 0.155 & 0.20 \\
(bulk) & & & & & \\
3.99 & 30 & 2.2 & 0.555 & 0.07 & 0.375 \\
2.01 & 45 & 6.7 & 0.455 & 0.015 & 0.53 \\
0.97 & 90 & 5.6 & 0.345 & 0 & 0.655 \\
0.48 & 150 & 13.7 & 0.29 & 0 & 0.71 \\
\hline
\end{tabular}

a Solvent, benzene; temp, $60^{\circ} \mathrm{C}$; [AIBN], $10 \mathrm{mmol}^{-1}$.

b The mole fraction of residual acrylic double bonds.

c The mole fraction of residual vinylic double bonds.

d The mole fraction of cyclic structural units calculated from the equation $f_{\mathrm{c}}=1-\left(f_{\mathrm{a}}+f_{\mathrm{v}}\right)$.

of $0.48 \mathrm{~mol} l^{-1}$.

Results of the polymerization in the presence of alkylaluminum chlorides are summarized in Table II. Spontaneous polymerization, i.e., in the absence of a free-radical initiator, occurred in the presence of any alkylaluminum chloride. The addition of the initiator induced a more rapid polymerization. Figure 3 shows the dependence of conversion after a 20 -min reaction period on the ratio of alkylaluminum chlorides to the monomer $(\mathrm{Al} / \mathrm{M})$. The rate of polymerization increased as the $\mathrm{Al} / \mathrm{M}$ molar ratio increased in the presence of $\mathrm{AlEt}_{2} \mathrm{Cl}$. In the presence of $\mathrm{AlEt}_{1.5} \mathrm{Cl}_{1.5}$ and $\mathrm{AlEtCl}$, the rate reached maximum values at an $\mathrm{Al} / \mathrm{M}$ molar ratio of 1.0.

The IR spectrum of the polymer obtained in the presence of $\mathrm{AlEtCl}_{2}$ is shown in Figure 2. The presence of the residual acrylic and vinylic double bonds in the polymer was observed as also in the
Table II. Effect of $\mathrm{Al} / \mathrm{M}$ molar ratio on the polymerization of $o$-vinylphenyl acrylate in the presence of alkylaluminum chlorides $^{\mathrm{a}}$

\begin{tabular}{cccll}
\hline $\begin{array}{c}\mathrm{Al} / \mathrm{M}, \\
\text { molar } \\
\text { ratio }\end{array}$ & $\begin{array}{c}\text { Time, } \\
\text { min }\end{array}$ & $\begin{array}{c}\text { Conver- } \\
\text { sion, } \\
\%\end{array}$ & $f_{\mathrm{a}}{ }^{\mathrm{b}}$ & $f_{\mathrm{v}}{ }^{\mathrm{c}}$ \\
\hline $\mathrm{AlEt}{ }_{2} \mathrm{Cl}$ & & & & \\
0.5 & 90 & 10.3 & 0.27 & 0.155 \\
1.0 & 40 & 15.8 & 0.315 & 0.145 \\
1.5 & 30 & 23.1 & 0.24 & 0.225 \\
2.0 & 20 & 14.8 & 0.235 & 0.27 \\
\hline $\mathrm{AlEt}_{1.5} \mathrm{Cl}_{1.5}$ & & & & \\
0.5 & 30 & 18.5 & 0.285 & 0.18 \\
1.0 & 15 & 16.9 & 0.255 & 0.14 \\
1.5 & 15 & 23.6 & 0.18 & 0.115 \\
2.0 & 40 & 12.2 & 0.225 & 0.11 \\
\hline $\mathrm{AlEtCl}_{2}$ & & & & \\
0.5 & 12 & 9.2 & 0.30 & 0.16 \\
1.0 & 7 & 13.3 & 0.265 & 0.08 \\
1.5 & 20 & 8.7 & 0.28 & 0.06 \\
2.0 & 20 & 6.9 & 0.305 & 0.115 \\
\hline
\end{tabular}

a Solvent, toluene; [M], $0.5 \mathrm{~mol} l^{-1} ;$ temp, $40^{\circ} \mathrm{C}$.

b The mole fraction of residual acrylic double bonds.

c The mole fraction of residual vinylic double bonds.

case of the conventional radical polymerization. A comparison of the spectra of polymers prepared under different conditions shows no substantial difference, except for that in the intensities of the absorptions due to unsaturations. The amount of the residual acrylic double bond was larger as compared with that of the vinylic one, except at the $\mathrm{Al} / \mathrm{M}$ molar ratio of 2.0 in the presence of $\mathrm{AlEt}_{2} \mathrm{Cl}$ as given in Table II. The amount of

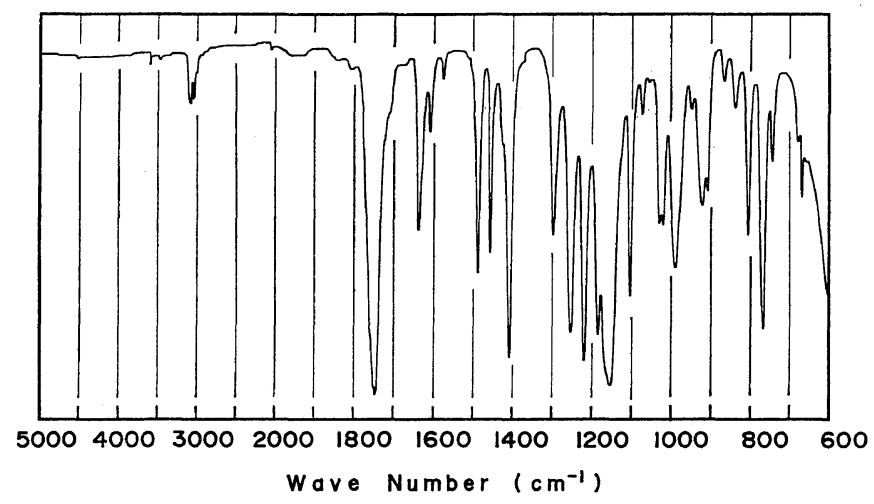

Figure 1. IR spectrum of $o$-vinylphenyl acrylate. 


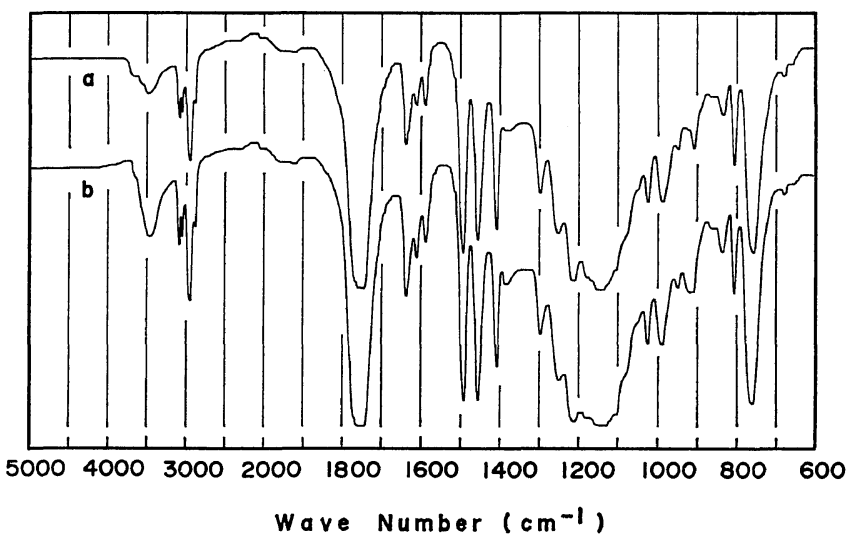

Figure 2. IR spectra of poly (o-vinylpenyl acrylate) prepared: (a) with $\mathrm{AIBN}$ at $60^{\circ} \mathrm{C}, f_{\mathrm{a}}=0.555$, $f_{\mathrm{v}}=0.07 ;$ (b) in the presence of $\mathrm{AlEtCl}_{2}, f_{\mathrm{a}}=0.30, f_{\mathrm{v}}=0.16$.

unsaturations was larger than that in the radical polymerization at the same monomer concentration.

The Cyclic Structure in Polymers and the Sequence Analysis

For the conventional radical polymerization of VPA, the propagation reactions including cyclization are

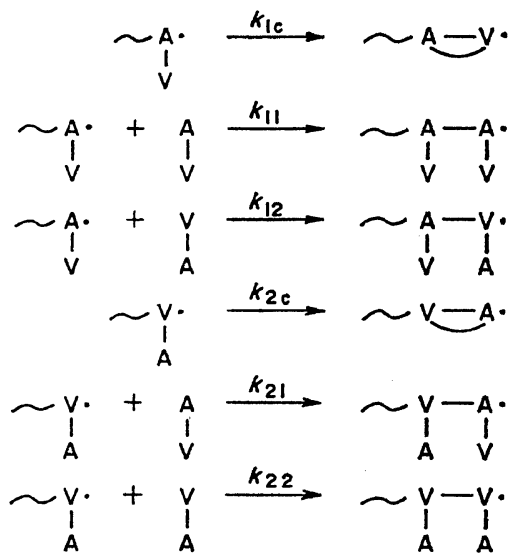

where $\mathrm{V}-\mathrm{A}$ represents $\mathrm{VPA}$, and $\mathrm{V}$ and $\mathrm{A}$ represent a vinylic and an acrylic double bond, respectively. As the vinylic double bond was completely consumed with a decrease in monomer concentration, the chain end of $\sim \mathrm{A}$ reacts predomiV

nantly through the reaction of eq 1 .

Both unsaturations partly remained also for the polymerization in the presence of alkylaluminum

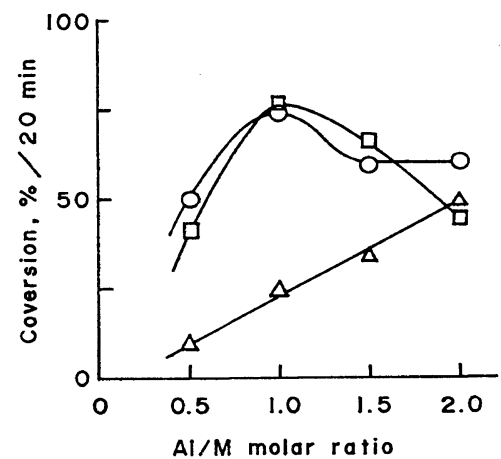

Figure 3. Dependence of conversion after 20-min reaction period on the $\mathrm{Al} / \mathrm{M}$ molar ratio: $(\Delta)$ in the presence of $\mathrm{AlEt}_{2} \mathrm{Cl} ;(\square)$ in the presence of $\mathrm{AlEt}_{1.5} \mathrm{Cl}_{1.5}$; (O) in the presence of $\mathrm{AlEtCl}_{2}$; solvent, toluene; [M], $0.5 \mathrm{~mol} l^{-1}$; [AIBN], $5 \mathrm{mmol} l^{-1}$; temp, $40^{\circ} \mathrm{C}$.

chlorides, and these amounts were larger than those for the radical polymerization; the results are entirely unlike those of APA. ${ }^{5}$ For the polymerization of APA, the residual unsaturation in the polymers obtained was only an allylic one, and the addition of alkylaluminum chlorides gave a marked increase to the cyclopolymerization tendency.

Thus the effect of addition of alkylaluminum chlorides to VPA was elucidated by the investigation of the cyclic structure in polymers and the sequence analysis. In the cyclopolymerization of VPA, there is the possibility of the formation of polymers containing six- and seven-membered rings, as indicated in (I) and (II). The structure 


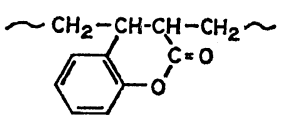

(I)

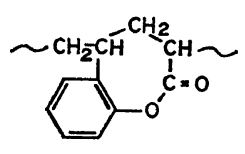

(II) of cyclized units was deduced from the procedure described in previous papers. ${ }^{5,6}$ The cyclized polymer is transformed into a methylated polymer corresponding to the copolymer of methyl acrylate and $o$-methoxystyrene by hydrolysis and diazomethane treatment. The methylated polymers (A and $\mathrm{R}$ ) were derived from the cyclized polymers obtained by the polymerization in the presence of $\mathrm{AlEt}_{2} \mathrm{Cl}$ and by conventional radical polymerization, respectively. By the same polymerization procedures, the alternating and the random copolymers of methyl acrylate and $o$-methoxystyrene (copolymers (A and $\mathrm{R}$ )) were prepared. Figure 4 shows the IR spectra of the methylated polymers and copolymers. The spectra of the copolymers (A and $\mathrm{R}$ ) are superimposable. A similar observation that there was no substantial difference between the random and the alternating copolymers of styrene-methyl acrylate and styrene -acrylonitrile was reported by Hirooka, et al. ${ }^{9}$ The methylated polymers (A and R) have IR absorption characteristics identical with those of the copolymers, except that the intensities of some absorption bands are slightly different. As the copolymers (A and R) should have the head-totail bondings, in common with other copolymers, ${ }^{10}$ the agreement of these spectra indicates that VPA polymerized to give polymers containing sevenmembered rings (II).

The NMR spectra of the copolymers and the methylated polymers are shown in Figure 5. A distinct difference in methoxy proton resonance is observed between the copolymer R (Figure 5 (a)) and the copolymer A (Figure 5 (b)). For the random copolymer of styrene-methyl acrylate, Ito, et al., observed that the resonance of methoxy proton was split into three peaks having poor resolution and suggested that this splitting is due to triad monomer sequences and configurational triad sequences. ${ }^{11}$ However, Hirooka, et al. ${ }^{9}$ and Izu, et al. ${ }^{12}$ reported that this methoxy proton resonance was split into five to seven peaks. For the alternating copolymer of styrene-methyl acrylate, the methoxy proton resonance showed three peaks to be assigned to co-isotactic, coheterotactic, and co-syndiotactic SMS triads, with a decreasing field, with $M$ and $S$ representing an acceptor and a donor monomer, respectively. ${ }^{9}$

In the spectrum of the copolymer A (Figure 5 (b)), there are four peaks at 3.11, 3.28, 3.40, and $3.52 \mathrm{ppm}$ in the region of methoxy proton resonances. Since the low-field component at 3.52

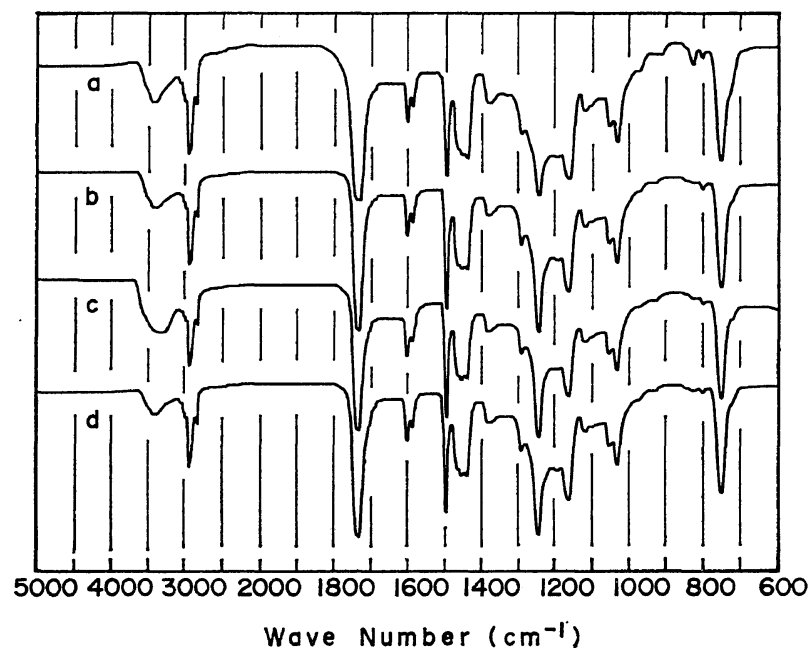

Figure 4. IR spectra of (a) the random and (b) the alternating copolymer of $o$-methoxystyrene and methyl acrylate, and the methylated polymer derived from poly(o-vinylphenyl acrylate) prepared: (c) with $\mathrm{AIBN}$; (d) in the presence of $\mathrm{AlEt}_{2} \mathrm{Cl}$. 


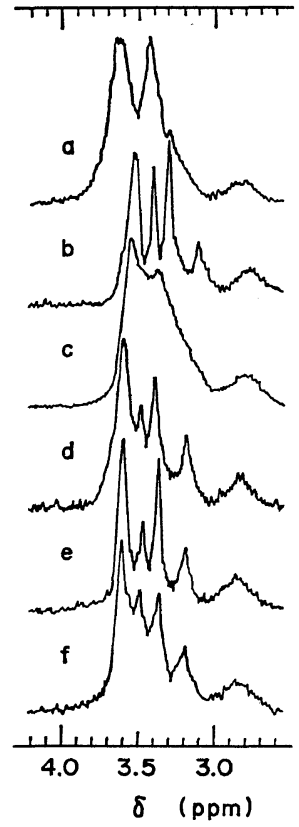

Figure 5. NMR spectra of (a) the random and (b) the alternating copolymer of $o$-methoxystyrene and methyl acrylate, and the methylated polymer derived from poly(o-vinylphenyl acrylate) prepared: (c) with $\mathrm{AIBN}$; (d) in the presence of $\mathrm{AlEt}_{2} \mathrm{Cl}$; (e) in the presence of $\mathrm{AlEt}_{1.5} \mathrm{Cl}_{1.5}$; (f) in the presence of $\mathrm{AlEtCl}_{2}$.

ppm is assigned to the methoxy proton resonance of $o$-methoxystyrene unit, that of methyl acrylate unit is split into three peaks which are very probably due to the co-tacticity of SMS triad sequences as in the case of the alternating copolymer of styrene-methyl acrylate. Although three peaks appear at 3.31, 3.34, and $3.64 \mathrm{ppm}$ in the spectrum of the copolymer R (Figure 5 (a)) as well, the methoxy proton resonance of methyl acrylate units shows broadening and poor resolution. This is due to a combination of triad monomer sequences, i.e., SMS, MMS, and MMM triads, and stereosequential effects. In the spectra of the methylated polymer A (Figure $5(\mathrm{~d}, \mathrm{e}, \mathrm{f})$ ), four peaks are observed at $3.17,3.36,3.48$, and 3.61 ppm. Since the methoxy proton resonance of $o$ methoxystyrene unit corresponds to the low-field component at $3.61 \mathrm{ppm}$, that of the methyl acrylate unit is well resolved into three components and is split mainly by stereosequential effects. Therefore, the triad monomer sequences must consist essentially of the SMS triad. In contrast, the methoxy proton resonances are mainly broadened and poorly resolved in the spectrum of the methylated polymer $\mathrm{R}$ (Figure $5(\mathrm{c})$ ) due, undoubtedly to configurational triad as well as to the monomer sequence effects. Thus, the triad monomer sequences consist of SMS, MMS, and MMM triads, which are ascribed to the random reaction via eq 1 to 6 in the cyclopolymerization. These results indicate that the characteristics of the polymerization of VPA in the presence of alkylaluminum chlorides are quite different from those of the conventional radical polymerization.

Regarding the cyclocopolymerization of APA and 2-AOEA with $p$-chlorostyrene in the presence of alkylaluminum chlorides, this result could be explained by the molecular complex mechanism; the polymerization was treated as a copolymerization between the intramolecular complex and the intermolecular complex which were formed in the process. $^{13}$ For the polymerization of VPA in the presence of alkylaluminum chlorides, therefore, it seems that the polymerization also proceeds according to copolymerization between the intramolecular complex (complex) ${ }_{1}$ and the intermolecular complex (complex) $)_{2}$, as shown in eq 7 and 8

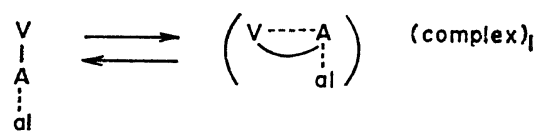

(7)<smiles>CC(C)(C)O[Mg]</smiles>

where al represents the alkylaluminum chlorides. Consequently, the acrylate units in the polymer will have styrene units on both sides, namely SMS triads. This mechanism explains the results from the sequence analysis of the methylated polymer A. However, the number of residual acrylic double bonds was greater than that of residual vinylic double bonds, as is shown in Table II.

The reason for this discrepancy was examined by copolymerization of the corresponding monovinyl compounds, $o$-vinylphenyl acetate and $o$ cresyl acrylate. Figure 6 shows the compositional data of the copolymerization in the presence of alkylaluminum chlorides. The copolymers obtained in the presence of $\mathrm{AlEt}_{1.5} \mathrm{Cl}_{1.5}$ had a near 


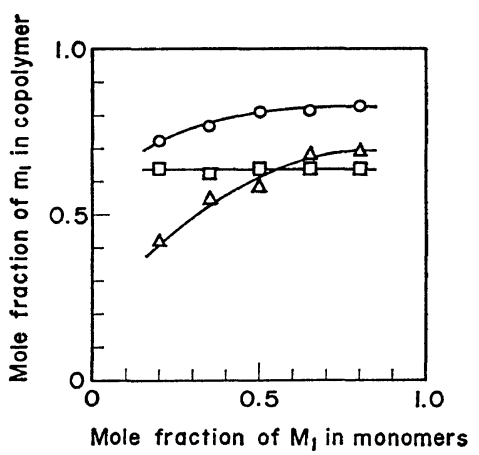

Figure 6. Variation of copolymer composition with monomer feeds in the system of $o$-vinylphenyl acetate $\left(\mathrm{M}_{1}\right)-O$-cresyl acrylate $\left(\mathrm{M}_{2}\right):(\triangle)$ in the presence of $\mathrm{AlEt}_{2} \mathrm{Cl} ;(\square)$ in the presence of $\mathrm{AlEt}_{1.5} \mathrm{Cl}_{1.5} ;(O)$ in the presence of $\mathrm{AlEtCl}_{2}$; solvent, toluene; $\left[\mathrm{M}_{1}\right]+\left[\mathrm{M}_{2}\right]$, $0.92 \mathrm{~mol} \mathrm{l} l^{-1} ;[\mathrm{Al}] /\left(\left[\mathrm{M}_{1}\right]+\left[\mathrm{M}_{2}\right]\right)$ molar ratio, 0.5 ; temp, $20^{\circ} \mathrm{C}$.

2: 1 composition $\left(m_{1}=0.64\right)$, irrespective of monomer feed ratio, and those obtained in the presence of $\mathrm{AlEtCl}_{2}$ slightly varied the composition. These results indicate that the copolymerization involved more complex steps than that in the Mayo-Lewis model. The free monomer, besides the intermolecular complex, should participate in the copolymerization. In every alkylaluminum chloride the proportion of styrene units was larger than that of acrylate units at a 1:1 molar ratio in feed. The deviation from the equimolar composition increased in the order of $\mathrm{AlEt}_{2} \mathrm{Cl} \leq \mathrm{AlEt}_{1.5} \mathrm{Cl}_{1.5}<$ $\mathrm{AlEtCl}_{2}$. It is very likely that these results correspond to a discrepancy in the amounts of the two residual unsaturations in the polymerization of VPA.

Conclusively, this discrepancy is interpreted as being caused by some participation of a reaction represented by eq 9 giving the corresponding amount of residual acrylic double bonds to the

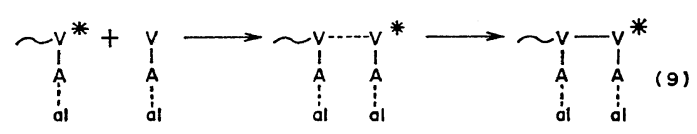

polymer. Hence, the SS sequence should be introduced without influence on the SMS triad by the occurrence of this reaction.

\section{REFERENCES}

1. W. E. Gibbs and J. M. Barton in "Vinyl Polymerization," Vol. 1, Part 1, G. E, Ham, Ed., Marcel Dekker, Inc., New York, N. Y., 1967, p 59.

2. G. B. Butler, J. Polym. Sci., 48, 227 (1960).

3. G. B. Butler and J. J. Van Heiningen, J. Macromol. Sci., Chem., A8, 1139 (1974).

4. G. B. Butler and M. A. Raymond, J. Polym. Sci., Part A, 3, 3413 (1965).

5. K. Yokota, N. Hirayama, and Y. Takada, Polym. $J ., 7,629$ (1975).

6. K. Yokota, T. Kakuchi, and Y. Takada, Polym. J. 8, 495 (1976).

7. G. Smets, P. Hous, and N. Devil, J. Polym. Sci., Part A, 2, 4829 (1964).

8. K. Fries and G. Fickewirth, Ber. 41, 367 (1908).

9. M. Hirooka, H. Yabuuchi, J. Iseki, and Y. Nakai, J. Polym. Sci., Part A-1, 6, 1381 (1968).

10. F. Shepherd and H. J. Harwood, J. Polym. Sci., Part B, 9, 419 (1971).

11. K. Ito and Y. Yamashita, J. Polym. Sci., Part B, 3, 637 (1965).

12. M. Izu, N. Yamamoto, and T. Kagiya, Abstracts, 24th Annual Meeting of the Chemical Society of Japan, Osaka, April 2, 1971, p 2034.

13. K. Yokota, T. Kakuchi, and Y. Takada, Polym. J., 10, 19 (1978). 